\title{
Studies in the Physiology of Parasitism. IX. The Effect on the Germination of Fungal Spores of Volatile Substances arising from Plant Tissues.
}

BY

WILLIAM BROWN, M.A., D.SC.

(From the Department of Plant Physiology and Pathology, Imperial College of Science and Technology, London.)

$\mathrm{T}$ the course of an investigation of the exosmosis of nutrient substances 1 from plant tissues into the infection drop (1), the observation was made that spores of Botrytis cinerea germinate better when petals of Rosa centifolia are placed in the same Petri dish, but out of contact with the water drops in which the spores are sown, than when they are absent. This remained an isolated observation for some years. When the subject was again taken up it was found that the capacity to stimulate $^{1}$ and, more generally, to influence the germination of fungal spores in some way or other by means of some volatile emanation could be demonstrated in the case of a large number of plants.

To the writer the main interest of these observations lies in the possible effect which volatile substances of plant origin may have in the establishment or non-establishment of fungal attack. It is felt, however, that it will be impossible to estimate their importance in questions of immunity and susceptibility until certain other nutritional problems have been dealt with. For this reason a more intensive study of these effects, and especially in relation to the chemical nature of the substances which produce the phenomena observed, has been postponed for the time being. Though the present account is of a somewhat preliminary nature, nevertheless enough .work has been done to show that volatile substances of plant origin may play a

1 The term 'stimulation' is here applied in the simple descriptive sense of increased germination; for the converse effect of reduced germination the word ' retardation' is generally used. It is fully recognized that effects of 'retardation' are also effects of 'stimulation', in particular of too strong stimulation in the usual physiological sense. Further, the use of the term 'stimulation' is not to be taken as prejudging the question as to whether the results are of a stimulatory as contrasted with a nutritional nature. The distinction between stimulus and nutrient is more easily drawn in theory than in practice, and in the case of the substances considered in the present paper-which most probably contain carbon and thus may enter directly into the carbon metabolism of the fungusany satisfactory distinction between stimulus and nutrient is at present impossible.

[Annals of Botany, Vol. XXXVI. No. CXLIII. July, 1922.] 
considerable, and a hitherto scarcely suspected, part in influencing the germination of the spores of fungal parasites.

The most significant statement in the literature dealing with this subject is that of Neger (2), who observed that spores of Bulgaria polymorpha germinate better in hanging-drop cultures when pieces of oak, beech, \&c., bark or wood, were placed in the bottom of the cell than when they were absent. Neger makes no statement as to the nature of the substances producing this effect.

As we are undoubtedly concerned here with volatile organic substances which produce stimulation of germination when present in very low concentration, reference may be made to the work of Duggar (3), who states that traces of ethyl alcohol or ether cause increased germination of the spores of Aspergillus. Duggar further records that distilled water which has been kept for some time in paraffin-lined flasks produces better germination of the spores of Aspergillus flavus than similar distilled water which has not been in contact with paraffin. Similarly the presence of vaseline in the hanging-drop cultures was found to improve the germination of Aspergillus flavus spores by ro to 20 per cent.

As a striking illustration of the influence of small traces of a volatile organic substance, we may cite the work of Beijerinck and van Delden (4), who describe a bacterium, called by them Bacillus oligocarbophilus, which did not grow in a nutrient containing a source of carbon food, but made appreciable growth in the absence of the latter from the cultural solution. These workers showed that the source of carbon in the case of this bacterium was some volatile carbonaceous substance present in the atmosphere, but which was not carbon dioxide. As to the nature of this substance, they were not able to make any statement beyond the fact that it was more abundant in laboratory than in greenhouse air.

The usual method of experiment in the present work was to lay the plant organs in question in large Petri dishes side by side with clean slides on which drops of an aqueous suspension of spores were placed. In a limited number of experiments, as will be mentioned later on, the plant structures were placed in the bottom of large containers and the slides placed in a rack above. As in general the effects were more marked when the leaves, \&c., were first bruised, the rule was made to put the leaves into the Petri dishes first, and then after a time the slides, so as to avoid any risk of droplets of plant juice falling on the slides. Also the bruising operation was always done at some distance from the Petri dishes, in most cases in another room. Petals of Rosa centifolia were always washed first of all to remove any adherent pollen.

As regards the cleaning of glassware, preparation of spore suspensions, \&c., the usual methods were adopted. Ordinary distilled water was used throughout. In the earlier stages of the work the Petri dishes were washed 


\section{Brown.-Studies in the Physiology of Parasitism. IX. 287}

after each experiment and allowed to dry out completely in the open air of the laboratory. This was to ensure that all traces of volatile substances from the preceding experiments had become dissipated before the dishes were used again. Latterly the method was adopted of strongly heating the dishes in a dry-air oven.

In the course of the investigation it was found that the moist filter- or blotting-paper, which it is usual in experiments of this kind to insert in the lids of Petri dishes for the purpose of preserving a moist atmosphere, produces a distinct effect on the germination of spores in the Petri dish. This effect will be described in the latter portion of this paper, but here it may be stated that filter- or blotting-paper which has lain moist in the lid of a Petri dish for some days gives off a volatile substance which reduces the amount of fungal germination taking place in pure water or in very dilute nutrient. Throughout the greater portion of this work parallel series were run, the one of Petri dishes set up with moist filter-or blotting-paper in the usual way, the other in which no such paper was present. In the latter case drying up of the drops was prevented by liberal moistening of the inner surface of the Petri dish.

It may be added that this paper effect proved to be of value from the experimental point of view, as it afforded a means of greatly reducing or actually suppressing the amount of germination which takes place in pure water in the case of some fungal spores. The stimulating effect arising from plant tissues becomes then more striking, as will appear from the tables given below.

In each experiment at least two, and usually four, Petri dishes were employed for each particular treatment. In each Petri dish two to four slides, each with two drops of the same spore suspension, were placed. Thus in each case abundant provision was made for accidental variations. The amount of germination was determined by measuring the length of germ-tube of a large number of spores (usually twenty-five from each drop) chosen at random from the central region of the drop, and dividing the total length of the germ-tubes by the number of spores counted. The restriction as to measuring germ-tubes from the central region of the drop is rendered necessary from the fact that under conditions of feeble nutrition germination is always somewhat better at the margins than in the centre of the drop. This point is also noted by Duggar in the paper referred to.

In practice it was found impossible to measure quantitatively the germination in all the drops which it was customary to set up. The number of Petri dishes used in any one experiment usually ranged from twenty to fifty, each containing four to eight drops, so that it was manifestly impossible to measure satisfactorily the amount of germination in each particular one. The large number of tests enabled the experimenter to arrive at a general impression of the result, and then as many measurements 
were made as it was judged would give an adequate representation of this impression. In many cases the differences were so pronounced that a limited number of measurements served for this purpose. Where the differences were less marked, more measurements were taken. In some cases, where differences appeared over even a large number of measurements, and where examination of all the drops gave no definite impression of difference, the results of measurement were ignored. The conclusion in such cases was that differences, if they did exist, were not large in amount, and therefore, in exploratory work such as the present is, the fuller examination of such effects should be postponed until such time as it appeared that the subject demanded it. The claims made in the present paper are on a very conservative basis, and are confined to the major and obvious results met with in the course of the work.

Most of the observations were made with spores of Botrytis cinerea, which proved in all respects to be the most convenient fungus for this work. Tests were also made with spores of Botrytis parasitica (Allii, the form occurring on onion), Monilia fructigena, Penicillium glaucum, Fusarium sp., and Colletotrichum Lindemuthianum.

The list of plants tested was as follows: petals of Rosa centifolia, leaves of Ruta macrophylla, Santolina Chamaecyparissus, Eucalyptus globulus, Pelargonium zonale, Choisya ternata, Chrysanthemum (garden vars.), Lavandula spicata, Foeniculum vulgare, Fuchsia (garden var.), Vicia Faba, Melittis melissophyllum, Amomum cardamomum, Andropogon Schoenanthus, Allium Schoenoprasum, Agapanthus umbellatus; bulb scales of onion; fruits and leaves of apple; rind of orange fruit; and tubers of potato.

The following table is typical of the result obtained when a few (one or two) bruised leaves are placed in Petri dishes side by side with slides on which lie drops of a suspension in water of spores of Botrytis cinerea. Moist blotting-paper was present in the Petri dish-lids in all cases. Spores of two different ages were used, the older giving feebler germination in water. In the case of the controls the figures are the average of Ioo counts ; the others are based on 50 counts. The measurements of germination were taken two days after the start of the experiment.

TABLE I.

Control
Amomum
Eucalyptus
Santolina
Ruta
Allium
Choisya
Lavender
Agapanthus
Apple (leaves)

$\begin{array}{cc}\text { Old spores. } & \text { Young spores. } \\ 0.07 & 2.03 \\ 0.94 & 3.48 \\ 0.52 & 2.60 \\ 0.60 & 3.44 \\ 1.74 & 3.68 \\ 0.00 & 0.00 \\ 2.16 & 5.08 \\ 0.32 & \text { similar to control } \\ 0.96 & 3.08 \\ 2.16 & 5.00\end{array}$




\section{Brown.-Studies in the Physiology of Parasitism. IX. 289}

Tests of unbruised leaves were run simultaneously, but only in the following cases was an increased germination noted:

$\begin{array}{lc} & \text { Old spores. } \\ \text { Control } & 0.07 \\ \text { Ruta } & 0.25 \\ \text { Choisya } & 0.35 \\ \text { Apple } & 0.22\end{array}$

A large number of experiments have been carried out along the lines of the one above described, and, while the results vary in degree in different experiments, the general result is convincing, viz. that certain volatile substances given off from plant tissues-especially when the latter are bruised - have a distinct effect on the germination of fungal spores. In the majority of cases the effect was found to be one of increased germination, but in some instances a distinct retardation, amounting in some cases to a complete inhibition, was produced. The most striking illustration of the latter so far observed is that of the onion. Tests have been made of leaves of Allium Schoenoprasum and of bulb scales of the ordinary onion, and in all cases it has been found that the addition of a small piece of onion tissue has a strongly repressing effect on the germination of Botrytis spores. This result is in agreement with the statements of Walker (5) on this point.

It is impossible at present to assert that one particular plant produces greater stimulation than some other one, as no means has been devised for regulating or measuring the intensity of the stimulating factor. Quite apart from questions of the varying amount of tissue and the varying amount of cell-bruising in different cases, there is also the different volatility of the various volatile compounds, their various solubilities in water, \&c. In practice it has been found that sometimes a particular plant gives the most striking result, in other experiments some other plant. But while no exact rule can be laid down in this respect, one can say broadly that some plants give good stimulation, others less so. Good material for showing stimulation are bruised leaves of Choisya, Ruta, and apple, though equally good results have been at times obtained with leaves of Eucalyptus, Amomum, and some others. It will be noticed that most of the plants tested are of an aromatic nature. The effect, however, is not confined to such oily plants, for distinct stimulation of growth has been obtained with bruised leaves of broad bean. In this case it was found that a considerable amount of tissue was required. On the other hand, only small stimulation has yet been seen in the case of lavender leaves.

Table I brings out an interesting experimental point, viz. that the stimulative effect is more readily discernible when the spores are of feeble germinative capacity. The ideal condition is when the spores in the control experiment remain ungerminated, in which case any stimulative effect is 
obvious at a glance. With young vigorous spores which may give an average germ-tube length of two to four divisions of the micrometer scale in the control tests, the result is not so obvious. On the other hand, spores of vigorous germinative capacity are desirable where a retarding effect is concerned. In many experiments, therefore, the practice has been to use both vigorous and feeble spores, so that suitable conditions were present for detecting both retarding and stimulating effects.

The vigorous type of spore is obtained from $I-2$ week old cultures on potato agar: the feebler spores from cultures of $4^{-8}$ weeks' age. In very old cultures still feebler germination is obtained, but the individual variations among the spores of a culture become more and more pronounced, not only when the spores are sown in water, but also when they are germinated in a good nutrient. This lack of uniformity places a limit beyond which the spores cannot be profitably used.

A method that proved useful for ensuring small germination in the control tests was to make use of the retardation due to blotting-paper already mentioned; this point will be illustrated later.

Apart from the effect of stimulation which results in an increased average germ-tube length, a distinct formative effect has been noted in many cases. This takes the form of increased stoutness of the germ-tube. In such cases it is not possible to give an adequate quantitative expression of the result. The stimulated and the control spores may on measurement give very much the same average germ-tube length, though the appearances presented in the two cases may be very different. In some cases, as will be noted subsequently, it is not possible to describe the effect either as a simple stimulation or a retardation, since the control germ-tubes take the form of long thin hyphae, whereas those formed in the presence of the plant tissue are shorter but much stouter.

Experiments have been carried out showing that the volatile stimulants are sufficient to increase markedly the parasitic powers of Botrytis spores. An experiment along these lines gave the results shown in Table II.

The experiment was set up in the general way already described, with the difference that several leaves of broad bean were put in, each leaf having on it a number of drops of the same spore suspension as was used for studying the amount of germination on the glass slides. The figures in the last column are in the form of fractions, the denominator of which gives the number of inoculations, the numerator the number of infections which had taken on the second day from sowing, at which time all the readings in the table were taken. It may be remarked that the increased parasitic effect was greater than the figures would indicate, as the greater percentage of infections in presence of the plant tissue was accompanied, on the average, by a much more advanced attack.

The effect produced by bruised bean leaves was only got by adding an 
Brown.-Studies in the Physiology of Parasitism. IX. 29 I

amount of bruised leaf tissue much greater than was found to be sufficient in the case of the other plants mentioned.

\section{TABLE II.}

$\begin{array}{lcc}\text { Leaves tested. } & \text { Av. germ-tube. } & \text { Attack of Bean leaves. } \\ \text { Control } & 0.18 & 6 / 28 \\ \text { Choisya } & 3.69 & \text { I } 4 / 17 \\ \text { Ruta } & 4.42 & 10 / 1 \text { I } \\ \text { Amomum } & 0.95 & 17 / 24 \\ \text { Foeniculum } & 0.97 & 11 / 20 \\ \text { Pelargonium } & 1.28 & 14 / 15 \\ \text { Apple } & 2 \cdot 48 & 16 / 20 \\ \text { Chrysanthemum } & 1.20 & 7 / 14 \\ \text { Broad bean } & 2.34 & 13 / 14\end{array}$

Special attention was given in this work to volatile substances given off by the tissue of apple fruit and potato tuber. The former of these gives distinct stimulation, the latter retardation of the germination of Botrytis spores.

As regards the cause of these effects, it was thought conceivable that they might be due to the action of the carbon dioxide of respiration. It was known that carbon dioxide represses germination if present in sufficient concentration (6). Also the possibility had to be considered that a slight concentration of carbon dioxide might counteract any slight alkalinity arising from the glass of the slides, it being known that a very slight degree of alkalinity had a pronounced inhibiting effect on the germination of Botrytis spores. The following experiment with apple slices shows that carbon dioxide is not the factor concerned.

Four thoroughly washed glass containers of three litres capacity were used. The various liquids employed (50 c.c. of each) were placed in glass vessels in the bottom; the apple slices, approximately the same weight in each, also in the bottom, and the slides (four in each) with the spore drops laid on a rack above. After two days the $\mathrm{CO}_{2}$ content of each container was analysed and the amount of germination determined in each drop. The following were the results obtained:

TABLE III.

\begin{tabular}{|c|c|c|}
\hline Container with: & $\mathrm{CO}_{2}$ content. & $\begin{array}{l}\text { Average of } 4 \text { counts of } \\
25 \text { spores each. }\end{array}$ \\
\hline $\begin{array}{l}\text { 5० c.c. } \mathrm{H}_{2} \mathrm{O} \text { : no apple } \\
\quad \text { : apple slices present }\end{array}$ & $0.0 \%$ & $\begin{array}{l}0.34(0.14 \text { to } 0.44) \\
1.80(1.38 \text { to } 2.12)\end{array}$ \\
\hline c. dil. $\mathrm{NaOH}$ : " " & $0.0 \%$ & $2 \cdot 3^{2}(2 \cdot 18$ to $2 \cdot 44)$ \\
\hline c. dil. $\mathrm{H}_{2} \mathrm{SO}_{4}$ : & & $2.25\left(1 \cdot 7^{2}\right.$ to $\left.2 \cdot 76\right)$ \\
\hline
\end{tabular}

The amounts of germination in the last three are all of the same order of magnitude. The figures in brackets give the limits of variation in the different counts. The germination in the absence of apple is distinctly least 
in all cases. This experiment proves conclusively that the carbon dioxide evolved by the apples is not the factor affecting the germination.

An experiment in which the germination in air was tested against that in 3 per cent. $\mathrm{CO}_{2}$ artificially made up gave the following result:

$$
\begin{aligned}
& \text { In air } \\
& \text { In } 3 \text { per cent. } \mathrm{CO}_{2} \quad " \quad=0.3 \mathrm{O}
\end{aligned}
$$

This further confirms the foregoing result.

A similar conclusion was reached for the retarding effect shown by potato tissue.

The stimulating effect of apple can be obtained with slices, with bruised, or with unbruised whole apples. As far as could be seen, the effect of the last mentioned was just as great as that of any of the others. The conclusion is thus reached that healthy unbruised apples can markedly stimulate spore germination in their vicinity.

In some tests an attempt was made to vary the amount of stimulation by using I, 2, 5, \&c., slices of apple, and as the final member of the series a considerable amount of pounded apple tissue. A distinct optimum effect was in some cases observed, that is, reduced germination was again met with in the last case. This optimum effect will be alluded to later in dealing with stimulation by ethyl acetate. In the present case it was not certain that fermentation in the pounded-up tissue may not have played a part in the result.

The following experiment, carried out in large containers, may be cited as confirming a statement already made, viz. that the effects described are more clearly discernible with somewhat feebly germinating spores than with vigorous ones.

\section{TABLE IV.}

$\begin{array}{clc}\text { Apple. } & \text { Spores. } & \text { Germination. } \\ \text { Absent } & \text { Old } & 0.6 \mathrm{I} \\ \text {, } & \text { Young } & 1.50 \\ \text { Present } & \text { Old } & 2 \cdot 43 \\ ,, & \text { Young } & 3.28\end{array}$

The ratio of stimulated to control spores is 4.0 for the old spores and $2 \cdot 2$ for young spores. The effect of stimulation is thus more striking in the former case.

The following somewhat detailed experiment may be quoted as illustrating among other things the retarding action arising from blottingpaper. The plants tested were: bruised leaves of Eucalyptus, slices of apple fruit and of potato tuber, and strips of rind of orange. Half the Petri dishes (all of which had been strongly heated in the oven) had blotting-paper in their lids. This had been kept wet for seven days before the plant tissue was put in. The other half of the Petri dishes were without 
blotting-paper. Eight Petri dishes were allotted to each plant, and eight were set up as controls, each lot being subdivided as follows :

2 with B.P. and containing watch-glass of water.

2 " " $"$ dil. $\mathrm{NaOH}$.

2 without B.P. and containing watch-glass of water.

$2 " \quad$ dil. $\mathrm{NaOH}$.

In each dish were two slides, each with two drops of the same spore suspension. There were thus eight drops under each treatment. After two days the state of germination was determined. In all cases no definite difference could be seen or measured between the germinations over water and the corresponding ones over dilute caustic soda, thus again showing that carbon dioxide is not the factor concerned. Each figure in the table represents the average of twenty-five spores taken from one drop, and each set of twenty-five measurements was taken from different drops. These figures will also serve to illustrate the degree of uniformity met with in these measurements.

TABLE V.

Experimental condition.

Without blotting-paper.

Control

Apple

Orange

Eucalyptus

Potato

With blotting-paper

Control

Apple

Orange

Eucalyptus

Potato
Amount of germination after 2 days.

$2.12, \mathrm{I} .60,2.08, \mathrm{I} .88$, ,

$\mathrm{I} \cdot 50, \mathrm{I} \cdot 72, \mathrm{I} \cdot 56, \mathrm{I} \cdot 60\}$

$3.44,3.16,3.12,3.24$

Inhibition in all cases 1

$$
\begin{aligned}
& 5 \cdot 84 \\
& 0.44^{2}
\end{aligned}
$$

$0.14,0.10,0.14,0.16$,

$2 \cdot 96,2.92,2.72,2.92$

Inhibition in all cases ${ }^{1}$ $3 \cdot 16,2.88$

Almost completely inhibited
Average.

$\mathrm{I} \cdot 7^{6}$

$3 \cdot 24$

0.00

$5 \cdot 84$

0.14

0.14

$2 \cdot 88$

0.00

3.02

$0.0+$

This experiment shows clearly the following points :

(I) That Botrytis spores are distinctly stimulated by the presence of apple tissue and of Eucalyptus leaves.

(2) That orange rind and potato tubers produce equally distinct depression of germination.

(3) That the presence of wet blotting-paper depresses germination.

Again it may be noted that the stimulating effect is best seen in the series where the control germination is feeble (i. e. when blotting-paper is present), whereas the retarding effects show best in the series where blotting-paper is absent and where accordingly the control germination is good.

Though the spores of Botrytis cinerea were found to be the most

1 Incipient germination on $4^{\text {th }}$ day.

2 This was the best germination seen in any of the eight drops. 
suitable objects for this work, similar results were also obtained with the spores of other fungi, as is shown in Table VI.

\begin{tabular}{ccccc}
\multicolumn{4}{c}{ TABLE VI. } \\
\multicolumn{1}{c}{ Fungus. } & With blotting-paper. & Without blottins-paper. \\
& Control. & Apple. & Control. & Apple. \\
Eotrytis cinerea & $0.0+$ & $3.5^{2}$ & $1.3^{8}$ & $4 \cdot 12$ \\
B. parasitica & 0.44 & 1.06 & $1.5^{2}$ & $1 \cdot 14$ \\
Fusarium sp. & 0.00 & 2.16 & 2.00 & 2.04
\end{tabular}

In the case of the other fungi tested in this experiment, measurements were not taken, but the following is a description of the results :

Penicillium glaucum: results follow the same lines as with Botrytis cinerea, i. e. apple without B.P. > apple with B.P., > control without B.P., $>$ control with B.P.

Colletotrichum Lindemuthianum: a small amount of germination in the control without blotting-paper : none at all in any of the others.

Monilia fructigena: with young spores the amount of germination in all cases was so great that measurement was impracticable: with older spores the amount of individual variation in germinative capacity is very great. This fungus appears to be very unsuited to work of this description.

The results with $B$. parasitica require further description. The figures in the above table give a very inadequate representation of the picture presented. All the germinations in presence of apple show stout germtubes, whereas the latter are very slender in the controls. The best illustrations of this effect have been met with in the case of this fungus. With Fusarium spores, a distinct stimulation by apple was only seen in the presence of blotting-paper. This fungus is also not very convenient for measurement, as it is generally not easy to decide where the germ-tube begins and the spore ends. The result with Colletotrichum is noteworthy as indicating the opposite response to the presence of apple tissue.

It is interesting also to note that with the exception of Monilia (for which no data were obtained) all the fungi tested reacted in the usual way to the presence of blotting-paper.

The effect of plant distillates and of various chemical substances was also tested.

Leaves of Ruta and of Pelargonium were placed in water in a retort and subjected to distillation. The distillates were then tested either by adding one drop of each to one drop of a spore suspension or by placing filter-paper wetted with the distillates in the Petri dishes. The control series had water in place of the distillate. The amount of germination in the various distillate preparations varied from four to ten times that in the controls. There is no doubt, therefore, as to the effects produced by the plant tissues being due to volatile substances arising from the latter. 
A number of pure chemical substances were also tested, including various esters of ethyl alcohol and several essential oils. The following is an experiment with ethyl acetate: In each of four 3 -litre containers 50 c.c. of water was placed and in order $0,1,2$, and Io drops of ethyl acetate added. The slides with spore drops were then put in and the lids of the containers immediately replaced. After two days the following figures for germination were obtained :

$\begin{array}{cccc}\text { Control. } & \text { I drop Eth. Ac. } & 2 \text { drops Eth. Ac. } & \text { 10 drops Eth. Ac. } \\ 0.36 & \text { I.82 } & \text { I.54 } & 0.4^{6}\end{array}$

These results indicate a distinct optimum effect, as was to be expected.

A rough comparison was made of several ethyl esters by testing the effect of a few c.c. of a saturated watery solution of each and of a tenth dilution of the same on the germination of Botrytis in Petri dishes. In all cases inhibition was shown in the presence of the saturated solutions, while stimulation appeared over the tenth-saturated solutions of ethyl acetate, malate, and citrate. In presence of even the dilute solution of ethyl oxalate, complete inhibition was still shown.

Any further comparison was not attempted, as obviously that would require a long investigation of itself. Nevertheless, these experiments show distinctly that the effects recorded earlier in this paper for plant tissues can be paralleled by the use of volatile organic reagents alone.

As good stimulation had been obtained with leaves of Eucalyptus and Pelargonium, tests were made with the oils of eucalyptus and geranium, chiefly with the former. Though several experiments were made with different amounts of oil, nothing in the nature of stimulation has yet been seen with either of these oils. Even one drop of oil in a large 3 -litre vessel is sufficient to inhibit spore germination. With water that has been shaken up with the oil and then diluted to various degrees, no definite stimulation has been seen at any point. It may of course be difficult to arrive at the suitable concentration, as the stimulative effect might only obtain over a very narrow range of concentration, but it is clear that with oil of eucalyptus stimulation is difficult to obtain, if it can be obtained at all, whereas good stimulation has, always been obtained with Eucalyptus leaves, as witness the experiment quoted on p. 293. It is not, of course, at all certain that the stimulating principle in Eucalyptus leaves is the so-called oil of eucalyptus at all. It may quite well be some other volatile substance present in the plant.

Oil of cloves was also tested, and it appeared that when present in very small amount it was highly toxic to fungal spores.

A fuller account will now be given of the blotting-paper effect which has already been several times mentioned. The magnitude of this effect 


\section{Brown.-Studies in the Physiology of Parasitism. IX.}

may be seen from several of the tables quoted above. It is shown equally well by blotting-paper and by the ordinary filter-paper. The method adopted to get the effect was simply to place discs of blotting- or filterpaper in the usual way in the lids of Petri dishes, to wet the papers with distilled or tap water, and to allow them to remain wet for a week. Control experinents showed that the effect began to appear in three or four days. On comparing a series of dishes in which the paper had remained wet for seven days with another series in which the paper was left dry for these seven days and was only wetted at the time the germination test was begun, it was found that the latter gave germination equal to that given in the absence of the paper, whereas the former showed reduced germination. A certain latent period is thus required for production of the effect. The effect is also shown as markedly when the wet paper is placed in the bottom instead of in the lid of the Petri dish, and is thus not due to interference by the paper with the conditions of aeration in the dish.

The method of producing the effect being thus known, experiments were carried out to determine in what ways it could be removed. The earlier work gave a certain amount of indication that the effect was produced more strongly in light than in darkness, and thus a photochemical action of light on the paper was suggested, resulting in the formation of some volatile substance, such as perhaps hydrogen peroxide or formaldehyde. Later experiments, however, have shown that the effect is obtained in much the same degree with wet blotting-paper in the dark, and all the results obtained indicate that the action is due to some organism or organisms growing in the moist paper. Thus after any treatment which would destroy organisms present in the paper the retarding effect does not appear. The following treatments have been shown to be effective in preventing the appearance of a retarding action: Sterilizing the paper in a moist condition (dry air sterilization of the paper is hardly allowable as this process much reduces its hygroscopic capacity); placing a few drops of chloroform in the Petri dishes (all traces of chloroform were found to have disappeared at the end of the incubation period); wetting the paper with dilute caustic soda, dilute copper sulphate, or potassium permanganate solution. In paper which is showing the retarding effect, this can be removed by washing with alcohol, followed by thorough rinsing with distilled water, or simply by the addition to the paper of a few drops of dilute permanganate solution. The effect thus appears to be due to biotic causes.

No attempt has been made to isolate the organism or organisms concerned, and thereby to produce the effects with pure cultures on the paper; nor"has the volatile substance been determined further than the experimental proof that it is not hydrogen peroxide. This was carried out as follows: Various dilutions of a 20-volume solution of hydrogen peroxide 
were added to the blotting-papers in a series of Petri dishes, by which means it was established that at a dilution of $\mathrm{I}$ in Ioo less retardation was caused than with blotting-papers which had been left wet with water for a week. At the end of the germination test, the addition of permanganate solution showed no definite reaction for hydrogen peroxide in the latter case, whereas a distinct rapid decoloration was shown in the former. The retarding effect on spore germination cannot thus be due to hydrogen peroxide.

The retarding effect of blotting-paper is not demonstrable when small traces of nutrient are present in the germination drop. The following test of germinations in various dilutions of turnip extract, carried out in Petri dishes with and without blotting-paper, illustrates this point:

\begin{tabular}{lccccc}
\multicolumn{7}{c}{ TABLE VII. } \\
No B.P. & T.E. $/ \mathrm{I}, 000$. & T.E. $/ 5$, ,000. & TE. $/ 25,000$. & T.E. $/ 100,000$ & Water. \\
B.P. & long & 3.76 & 3.12 & 2.88 & $2.5^{2}$ \\
long & 4.12 & 0.74 & 0.20 & 0.20
\end{tabular}

The effect, therefore, is only demonstrable in sowings in water or in extremely dilute nutrient.

\section{Discussion.}

The experiments described in the present paper point to a marked degree of sensitiveness on the part of fungal spores to the presence of traces of volatile organic substances in the atmosphere to which the spores are exposed during germination. Such stimulation is not large absolutely, and accordingly is only in general demonstrable when the spores are placed in conditions of very limited fond supply, as for example in pure water. The behaviour of fungal spores in water is a matter of considerable importance in the study of pathology. The bearing of the results of this paper on such study may now be indicated.

Germination studies are in many cases carried out in an incubator, and usually in the presence of other fungal cultures. Every one who has worked with fungi knows the characteristic 'fungous' odour which clings to an incubator which is in constant use. In the case of germination studies in which the ordinary cultural media are used, any effect arising from the atmosphere would probably be negligible; when, on the other hand, one is dealing with germinations in water it is not at all certain that the effects produced by these volatile substances could be ignored. As a case in point, we may adduce the effects produced by biotting-paper already described. Here there seems no doubt that the effects in question are produced by the action of some organisms growing on the moist paper and giving off some volatile organic substance deleterious to germination.

In carrying out studies of germination in water, one should therefore 
take steps to reduce disturbing atmospheric factors to a minimum. In cases where relative effects only were being considered, any disturbance arising from volatile substances would probably be of less consequence, but if it was sought to determine the absolute amount of germination, the result obtained, e.g. in the presence of a large number of other cultures, would in all probability not represent the intrinsic germinating capacity of the fungus under investigation. In particular the custom of placing moist paper in the lids of Petri dishes in accurate studies of germination is not to be recommended unless proper control measures are taken. Furthermore, one may ask in this connexion how far the failure, so often reported, to obtain vigorous attack under laboratory conditions with organisms which readily produce attack under field conditions may not be due to some such influences as are here indicated.

The possible significance of the results of the present paper for the physiological analysis of pathological problems will now be discussed: (I) in relation to the conditions in the infection drop, (2) in relation to growth of the fungus after penetration of the host.

It was shown in earlier papers of this series that the conditions present in the infection drop are in general those of feeble nutrition. The vigour of germination in the infection drop-a factor of primary importance in deciding whether attack is possible or not-has been shown in No. VIII of the present series to be influenced by the passive exosmosis of food substances from the host tissue into the infection drop. The present results show that, granted suitable conditions, a like effect can be produced through the action of volatile substances arising from the plant and accumulating in the atmosphere. A priori one would expect this latter effect to be least in the open field. On the other hand, one would anticipate that it would play a greater part under conditions of storage. Here the atmosphere is stagnant and volatile substances can accumulate to a degree comparable with the conditions which gave results in the present experiments. To cite particular instances, one may confidently state that the atmosphere of an apple store is very favourable to Botrytis germination; and that the converse is true for the atmosphere of a potato store.

As regards the effect of volatile constituents of the plant on the growth of the fungus, once the latter is inside, little can be said at present. Unpublished experiments have clearly shown that the capacity of crude unboiled plant extracts to cause germination and growth of fungal spores is in many cases very different from that of the boiled extracts. An extreme case of this is afforded by onion juice, which inhibits Botrytis germination when in the unboiled condition, whereas when boiled it allows ready germination and growth. An investigation of this phenomenon is in progress and, though it is fairly clear that other factors also are concerned, the influence of volatile elements is being kept in view. 
The question of a specific action on a particular fungus of the volatile substances from a particular plant has scarcely been touched. This is a problem of considerable experimental difficulty, and as such it has been decided not to follow it up for the present. The difficulty in question is one of special methods rendered necessary by the nature of the problem. The active substances are volatile and produce their effects when present in small quantity. A quantitative examination would therefore involve considerable technical difficulties. As a further difficulty one would have to reckon with the strong probability that the curve expressing stimulation in terms of concentration would show a pronounced optimum, so that in practice one would not be certain, short of considerable experimentation, whether a small effect in any particular case was due to too much or too little of the stimulant. The interpretation of the result in any particular experiment would thus not be easy, especially as at the present there seems to be no ready means of regulating or measuring the concentration of the stimulant. As an illustration of this difficulty we may refer to the experiment quoted on p. 294. The presence of apple tissue was there seen to produce distinct stimulation of Botrytis cinerea spores, but to inhibit spores of Colletotrichum. There would appear to be a certain appositeness in this result-that Botrytis spores are stimulated by volatile substances arising from apple fruit, which is one of its natural hosts, whereas Colletotrichum, which does not occur on apple, is not so stimulated. But this conclusion would be premature, as it is quite possible that under suitable conditions the spores of the latter fungus could also be stimulated by the presence of apple tissue. Obviously a considerable amount of work is still required in this connexion.

\section{SumMary.}

I. The germination of Botrytis cinerea spores is increased by the action of volatile substances arising from certain plant tissues, such as apple leaves and fruit, leaves of Ruta, Eucalyptus, \&c.

2. In other cases reduced germination or even inhibition is producedviz. with tissue of potato tuber, onion leaves or bulb scales.

3. Reduced spore germination due to volatile substances produced by growth of organisms in wet filter- or blotting-paper is described.

4. Similar stimulating and retarding effects can be produced by the action of simple chemical substances such as ethyl acetate.

5. A number of other fungi were tested in these respects and found to behave similarly to Botrytis cinerea.

6. The bearing of these results on general mycological technique and on problems of physiological parasitism is discussed. 


\section{LITERATURE CITED.}

1. Brown, W.: On the Exosmosis of Nutrient Substances from the Host Tissue into the Infection Drop. Ann. Bot., xxxvi. IOI-J9, I922.

2. Neger, F. W.: Förderung der Keimung von Pilzsporen durch Exhalationen von Pflanzenteilen. Natw. Zs. f. Land- u. Forstwirtschaft, ii. 484-90, I904.

3. Duggar, B. M.: Physiological Studies with Reference to the Germination of certain Fungous

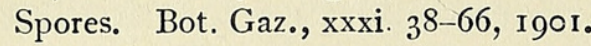

4. Beijerinck, M. W., and van Delden, A.: Uber eine farblose Bakterie, deren Kohlenstoffnahrung aus der atmosphärischen Luft herrührt. Centr. f. Bakt., II, x. 33-47, I 903 .

5. Walker, J. C. : Onion Smudge. Journ. Agr. Res., xx. 685-72I, I 92 I.

6. Brown, W. : On the Germination and Growth of Fungi at various Temperatures and in various Concentrations of Oxygen and of Carbon Dioxide. Ann. Bot., xxxvi. 257-83, I922. 


\section{$2 \mathrm{BHL}$ Biodiversity Heritage Library}

Brown, William. 1922. "Studies in the physiology of parasitism. IX. The effect on the germination of fungal spores of volatile substances arising from plant tissues." Annals of botany 36, 285-300.

https://doi.org/10.1093/oxfordjournals.aob.a089807.

View This Item Online: https://www.biodiversitylibrary.org/item/234428

DOI: https://doi.org/10.1093/oxfordjournals.aob.a089807

Permalink: https://www.biodiversitylibrary.org/partpdf/319043

\section{Holding Institution}

Smithsonian Libraries

\section{Sponsored by}

Biodiversity Heritage Library

\section{Copyright \& Reuse}

Copyright Status: Not in copyright. The BHL knows of no copyright restrictions on this item.

This document was created from content at the Biodiversity Heritage Library, the world's largest open access digital library for biodiversity literature and archives. Visit BHL at https://www.biodiversitylibrary.org. 